\title{
Medical Image of the Month: Giant Bulla
}

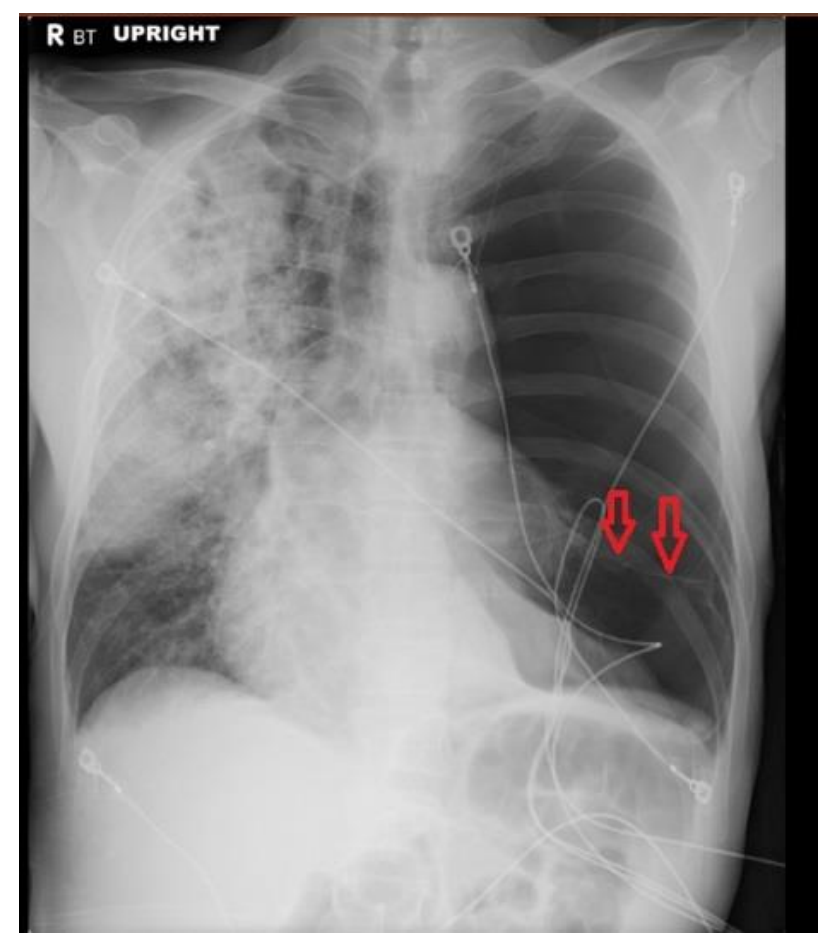

Figure 1. A chest radiograph demonstrates marked oligemia of the left lung with displacement of the cardiomediastinal silhouette to the right. Subtle, linear lung parenchymal markings are noted in the base of the left lung hinting at extensive bullous disease and not a pneumothorax (red arrows).

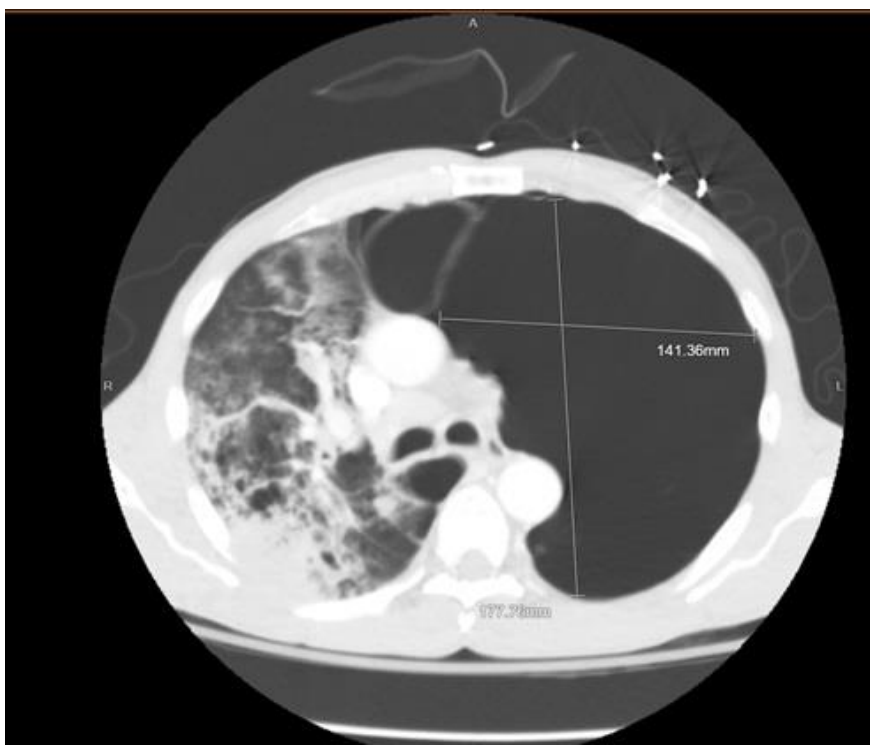

Figure 2. A CT of the chest with contrast in lung windows demonstrates a giant bulla centered in the left upper lobe. Adjacent bullous disease is also present. 
Clinical Background: A 49-year-old gentleman with an extensive smoking history who was transferred from an outside hospital for higher level of care for management of his acute hypoxemic respiratory failure. His outside chest radiograph (Figure 1) demonstrated marked oligemia of the left lung with displacement of the cardiomediastinal silhouette to the right. Subtle linear parenchymal markings are noted in the lower lobe suggesting bullous disease. There is extensive airspace disease of the right lung. A CT of the chest (Figure 2) demonstrated extensive bullous disease with a giant bulla noted in the left upper lobe. The patient was transferred to the MICU for further management of his hypoxemic respiratory failure. A CT surgery consult was obtained, and he was deemed not to be a surgical candidate given his tenuous clinical status.

Discussion: A bulla is defined as an air-containing space measuring greater than $1 \mathrm{~cm}$ in diameter and surrounded by a thin wall which is less than $1 \mathrm{~mm}$ thick. Bulla are usually located in a subpleural location and can be seen with emphysema - both paraseptal and centrilobular types. A giant bulla is defined as a bulla occupying at least $30 \%$ of a hemithorax. In this case, the patient had a giant bulla centered in the left upper lobe.

Giant bullae typically develop because of long-term cigarette smoking, which is the most likely cause in this case. Bullous lung disease has also been associated with HIV infection and intravenous use of methadone, methylphenidate, or talc-containing drugs.

In asymptomatic patients, smoking cessation is recommended to prevent further progression. In dyspneic patients with COPD, medical therapy with bronchodilators, inhaled corticosteroids, supplemental oxygen, and pulmonary rehab are recommended. In patients who have dyspnea despite medical optimization or who have issues with a spontaneous, secondary pneumothorax, a bullectomy may be beneficial.

Contraindications to a bullectomy include ongoing cigarette smoking, significant comorbid disease, poorly-defined bullae on chest imaging, pulmonary hypertension, and other comorbid conditions that make surgery high risk.

Leslie Littlefield MD and Mohammed Fayed MD

UCSF Fresno

Fresno, CA USA

\section{References}

1. Rosado-de-Christenson M, Abbott GF. Diagnostic Chest Imaging. $2^{\text {nd }}$ edition. Canada: Amirsys; 2012; Section 1, p 15.

2. Diaz PT, Clanton TL, Pacht ER. Emphysema-like pulmonary disease associated with human immunodeficiency virus infection. Ann Intern Med. 1992 Jan 15;116(2):124-8. [CrossRef] [PubMed]

3. Palla A, Desideri M, Rossi G, Bardi G, Mazzantini D, Mussi A, Giuntini C. Elective surgery for giant bullous emphysema: a 5-year clinical and functional follow-up. Chest. 2005 Oct;128(4):2043-50. [CrossRef] [PubMed] 